\title{
Optimal order quantity considering carbon emission costs, defective items, and partial backorder
}

\author{
Yosef Daryanto $^{\mathrm{a}^{*}}$ and Bellachintya Reira Christata ${ }^{\mathrm{a}}$
}

\begin{abstract}
${ }^{a}$ Department of Industrial Engineering, Universitas Atma Jaya Yogyakarta, Jl. Babarsari 43, Yogyakarta, Indonesia

\begin{tabular}{l}
\hline C H R O N I C L E \\
\hline Article history: \\
Received November 6, 2020 \\
Received in revised format \\
January, 25, 2021 \\
Accepted March 52021 \\
Available online \\
March 5 2021 \\
\hline Keywords: \\
Economic order quantity \\
Defective items \\
Partial backorder \\
Carbon emission \\
\\
\hline
\end{tabular}

To respond to the adoption of carbon pricing regulations, researchers and industry are developing low carbon inventory models that can meet emission reduction targets while maintaining company profits. The challenge is getting tougher when the company is still facing problems related to imperfect product quality. This research solves this problem by developing an economic order quantity (EOQ) model by considering several sources of carbon emissions, as well as the influence of the defective rates, different demand rates, selling price and holding cost for defective products, and shortages backorder. The objective function of the formulated mathematical model is to minimize the total costs which include the emission costs. A numerical example is developed to illustrate the model based on the previous data set. Sensitivity analysis is also carried out to validate the model and to learn more about the system characteristics. The total emissions are calculated and the affecting factors are identified.
\end{abstract}

(C) 2021 by the authors; license Growing Science, Canada.

\section{Introduction}

Global warming and other environmental problems influence many aspects of our economy. Hence, efforts to reduce the negative impact of business activities have become global awareness. No exception to the negative impact of logistics activities. One emerging concern in today's logistics management is to build a sustainable system with a minimum environmental impact. Particularly, the implementation of carbon emission regulation by many governments raises the need for industries to develop sustainable logistics systems, including inventory systems that produce as few carbon emissions as possible. For example, Bonney and Jaber (2011) developed an inventory model that reflects the concern on emission reduction. Several factors are considered such as emissions from transportation activities and the waste generated by each lot. The emission costs become part of the total inventory cost; hence, an optimal decision can be derived to minimize the total cost. The study on low carbon inventory management still needs many explorations, regarding different issues in the real inventory system. One of the important challenges faced by many companies is the unavoidable problem of product quality. Our study will solve the economic order quantity (EOQ) decision when a percentage of defective items exist in each delivery lot, and the company (i.e., a retailer) searches for carbon emission reduction. This issue has attracted several researchers such as Kazemi et al. (2018) and Wee and Daryanto (2020). The studies employed quality inspection to separate the defective items from the perfect ones at the arrival of the order. Kazemi et al. (2018) assigned different holding costs for different categories of products, while Wee and Daryanto (2020) neglected the holding cost of the defective items. However, both studies followed the assumption from Wahab and Jaber (2010) in which the defective items will be sold at the end of the inspection process. Selling defective items at one time is not always the case. In most cases, retailers have to keep these defective products for some time while selling them at a lower price. This was stated by Teng \& Hsu (2013) assuming that demand for defective products is smaller than demand for the perfect ones. Therefore, our study develops an EOQ model considering the effects of defective rates, the separation between the perfect and defective products, different demand rates, selling price, and holding cost for defective products, and carbon emissions produced during transportation and inventory holding. The mathematical model is examined with a numerical example to test the results including the

\footnotetext{
* Corresponding author

E-mail address: yosef.daryanto@uajy.ac.id (Y. Daryanto)

C 2021 by the authors; licensee Growing Science.

doi: $10.5267 /$ j.uscm.2021.3.002
} 
sensitivity analysis. Moreover, the effect of each parameter on the total emissions is studied. The results of this study can be a guideline for the managerial decision to develop a profitable and sustainable inventory system.

The remainder of this paper is arranged as follows. In the second section, we present previous research on the EOQ models with carbon emission consideration and the effect of imperfect quality products. Section 3, initially, presents the problem assumption and notation list and then explains the formulated model. Section 4 discusses the model by providing a numerical example, the corresponding sensitivity analysis, and a discussion on the findings. Finally, section 5 concludes the study.

\section{Literature Review}

\subsection{Sustainable inventory model}

Since the development of the economic order quantity (EOQ) model a century ago, research on inventory models has attracted much attention. Lately, with increasing efforts to build a more environmentally friendly industry, many researchers have studied aspects of sustainability in inventory management. Some terminology has been proposed such as "environmentally responsible inventory model," "carbon-constrained EOQ," "sustainable EOQ," "sustainable order quantity (SOQ)," "low carbon EOQ," etc. Bonney \& Jaber (2011) proposed a simple non-classical model that includes vehicle emissions and waste disposal costs, in addition to ordering costs, purchasing costs, storage costs, and transportation costs. The EOQ model considered the effect of product returns, vehicle emissions costs, delivery distances, vehicle speeds, and waste disposal costs. Carbon footprint can be used to measure the total amount of $\mathrm{CO}_{2}$ emissions of an activity, such as ordering goods, producing, transporting, storing, consuming, and disposing or recycling their products. In their study, researchers calculated the cost of carbon emissions in their supply chain decision models. Previous studies applied a direct accounting approach to translating environmental aspects of carbon emissions into economic parameters (Benjaafar et al., 2013). According to Chen et al. (2013), adjustments in order quantities can help companies to reduce emissions from their regular operations. Battini et al. (2014) considered the costs of variable repairs and emissions, storage costs and warehouse emissions, and emissions from the collection and disposal of obsolete materials. Soleymanfar et al. (2015) referred to research from Battini et al. (2014) and developed a sustainable lot-sizing model with a partial backorder taking into account carbon emissions from inventory obsolete. Hua et al. (2016) studied a supply model for perishable items in which demand depends on the level of freshness of the product and uses carbon emissions as one of the constraints. Carbon emissions come from shipping/transporting, storing, and deteriorated material. Wangsa (2017) incorporated emissions from internal energy generation. Lee et al. (2017) examined the impact of time uncertainty and multi-modal transportation on a sustainable EOQ model in international supply chains. The decision variable is the number of orders and the reorder point because uncertainty can lead to shortages. Taleizadeh et al. (2020) considered the existence of all-unit discounts on EOQ models with carbon emissions and partial backorder. The studies above take into account the cost of emissions based on the carbon tax system. Following the previous studies, our model will consider the emissions from product deliveries and storage and the retailer obligated to carbon tax regulation.

\subsection{Inventory model with defective items}

Other studies have developed inventory models with the assumption that not all products received conform to quality specifications. Porteus (1986) and Rosenblatt \& Lee (1986) exhibited the relationship between imperfect quality and lot size. Schwaller (1988) assumes that defective goods received in lots will result in additional inspection costs. Salameh \& Jaber (2000) studied the EOQ model with the effect of a defective product whose probability distribution was known. They assume that defective goods are sold as a batch at the end of the inspection period at lower prices. In contrast to these assumptions, Teng \& Hsu (2013) considered selling these defective products gradually depending on the customer demand rate. The holding costs are different from the perfect products.

Several studies considered the simultaneous effect of imperfect quality and carbon emissions on EOQ models. Digiesi et al. (2012) studied sustainable EOQ by considering the possibility of repairing defective components rather than buying a new one. They consider the environmental costs of producing and transporting new parts, and for disposing of the replaced units. Kazemi et al. (2018) incorporated the effect of imperfect quality and studied the optimal order quantity. Wee \& Daryanto (2020) added the effect of shortages with a full backorder on total costs and carbon emissions. Recently, Daryanto et al. (2020) extended the low carbon EOQ model considering the holding cost and emissions from the defective items. However, the developed low carbon EOQ models did not consider the partial backorder situation. Our study fills this important gap because, in real business, a percentage of customers will go to other retailers or find other products when the original order cannot be satisfied.

In this study, an economic order quantity (EOQ) model is developed by considering carbon emissions, as well as the effects of defective rates, demand rates for defective items, shortage back orders, and the existence of discounts for defective products. The state of the art of this study is shown in Table 1 which shows a comparison with previous studies. 
Tabel 1

Summary of literature on EOQ model with defective items and carbon emissions

\begin{tabular}{|c|c|c|c|c|c|}
\hline Author(s) & 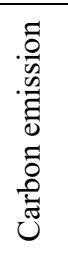 & 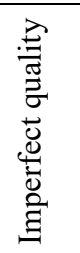 & 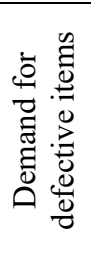 & 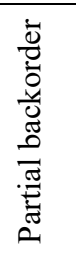 & 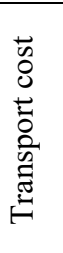 \\
\hline Porteus (1986) & & Yes & & & \\
\hline Schwaller (1988) & & Yes & & & \\
\hline Salameh \& Jaber (2000) & & Yes & & & \\
\hline Bonney \& Jaber (2011) & Yes & & & & \\
\hline Digiesi et al. (2012) & Yes & Yes & & & \\
\hline Teng \& Hsu (2013) & & Yes & Yes & & \\
\hline Chen et al. (2013) & Yes & & & & \\
\hline Battini et al. (2014) & Yes & & & & \\
\hline Soleymanfar et al. (2015) & Yes & & & & \\
\hline Hua et al. (2016) & Yes & & & & \\
\hline Lee et al. (2017) & Yes & & & & \\
\hline Kazemi et al. (2018) & Yes & Yes & & & \\
\hline Taleizadeh et al. (2020) & Yes & & & Yes & \\
\hline Wee \& Daryanto (2020) & Yes & Yes & & & \\
\hline Daryanto et al. (2020) & Yes & Yes & Yes & & Yes \\
\hline This research & Yes & Yes & Yes & Yes & Yes \\
\hline
\end{tabular}

\section{Model Development}

\subsection{The problem, assumptions, and notations list}

A retailer orders $Q$ units of product to fulfill their customers' demand per inventory cycle. Due to supplier reliability problems, the retailer finds certain defective products in each delivery. Recorded data shows the probability of defective products. Upon receiving, the retailer conducts a quality inspection of all products and separates the defective products in a different area. Then, due to lower quality and value, the defective products are sold at a lower price, and the demand rate for these products is much lower. The retailer is willing to minimize the total cost by optimizing the order quantity. However, due to the campaign on carbon emission reduction, the government charges carbon tax which is equivalent to the total emissions amount. The retailer must consider this additional cost in the total cost function.

Further, the EOQ problem works under the following circumstances:

1. The inspection can identify and separate the defective products perfectly. During the inspection period, customer demand is fully satisfied due to the high inspection rate. Moreover, the probability of defective products is known. This set of assumptions is similar to Salameh \& Jaber (2000), Wahab \& Jaber (2010), Kazemi et al. (2018), etc.

2. The retailer allows inventory shortages and partial backorder occurs from a percentage of customers.

3. $\mathrm{CO}_{2}$ is directly emitted from order transportation and electricity consumption in product storage.

Our model uses the following parameters and variables:

\section{Parameters}

$d_{1} \quad$ demand rate of good product (units/year)

$d_{2} \quad$ demand rate of defective product (units/year); $d_{1}>d_{2}$

$C_{o} \quad$ a fix order cost (\$/cycle)

$C_{p} \quad$ purchasing cost (\$/unit)

$C_{i} \quad$ inspection cost (\$/unit)

$C_{h 1} \quad$ holding cost of good items (\$/unit/year)

$C_{h 2} \quad$ holding cost of defective items (\$/unit/year)

$C_{b} \quad$ penalty cost due to backorder (\$/unit)

$C_{l} \quad$ lost sales cost (\$/unit)

$C_{d} \quad$ transportation setup cost (\$/cycle)

$C_{f} \quad$ average fuel price ( $\$ /$ liter)

$C_{t} \quad$ carbon tax rate $\left(\$ /\right.$ tonCO $\left.\mathrm{C}_{2}\right)$

$\alpha \quad$ defective rate in $Q$,

$f(\alpha) \quad$ probability density function (pdf.) of $\alpha$

$E[$.] expected value operator of $\alpha$ 


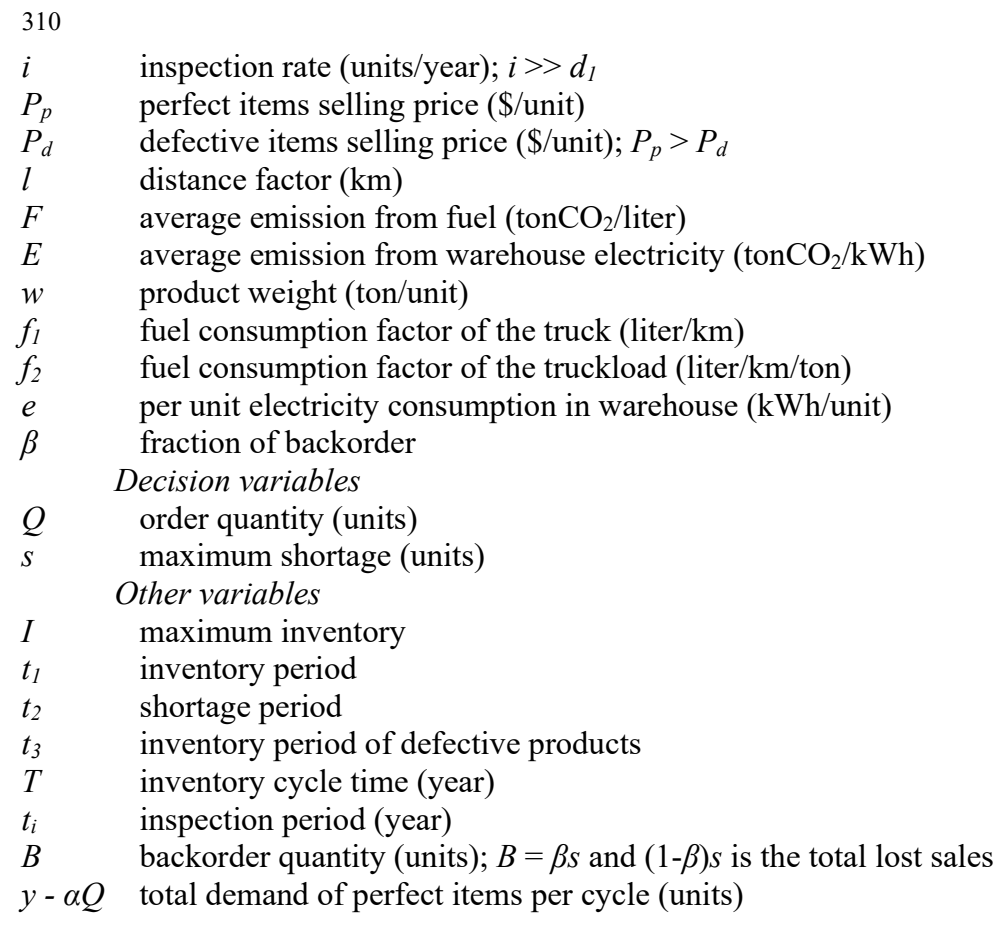

\subsection{Model formulation}

The inventory model is shown in Fig. 1. From the EOQ model with imperfect quality in Maddah \& Jaber (2008), separation and gradual depletion of the defective items in Teng \& Hsu (2013) are considered, and finally, the effect of emission cost in Wee \& Daryanto (2020) is incorporated with a partial backorder.

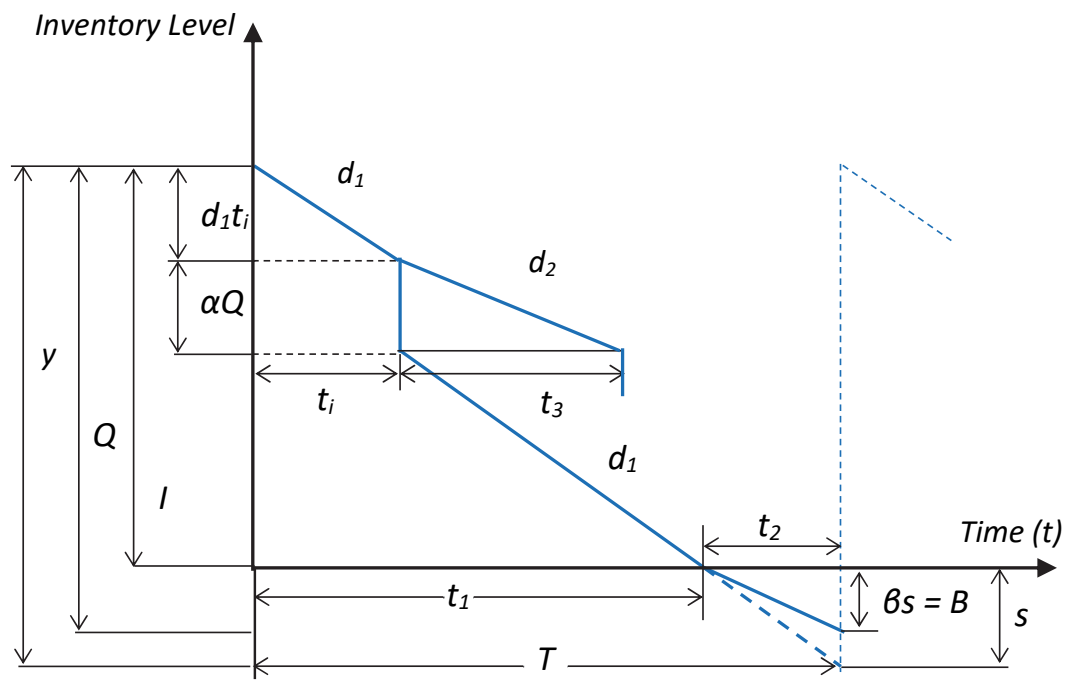

Fig. 1. The graphical inventory model

The inspection lasted for $t_{i}$, that is

$$
t_{i}=\frac{Q}{i}
$$

After the inspection, $\alpha Q$ of defective items are placed in a different area of the shop. The inventory is continuously decreasing for both the perfect and imperfect items at a different rate. The perfect items inventory reaches zero at $t_{l}$, while the defective items are depleted at $t_{3}$. Shortages occur during $t_{2}$ before the arrival of the next delivery, in which only $\beta S$ units are back-ordered. This arrangement resulting in the following equations: 
$t_{2}=\frac{\beta S}{\beta d_{1}}=\frac{S}{d_{1}}$

$t_{3}=\frac{\alpha Q}{d_{2}}$.

The length of the inventory cycle is

$$
T=t_{1}+t_{2}
$$

hence, substituting Eq. (2) and Eq. (3) into Eq. (5), we have

$$
T=\frac{(1-\alpha) Q-\beta S}{d_{1}}+\frac{S}{d_{1}}=\frac{(1-\alpha) Q-\beta S+S}{d_{1}}=\frac{(1-\alpha) Q+(1-\beta) S}{d_{1}} .
$$

Considering the portion of defective items, we have a similar result as

$$
T=\frac{y-\alpha Q}{d_{1}}=\frac{Q+(S-\beta S)-\alpha Q}{d_{1}}=\frac{(1-\alpha) Q+(1-\beta) S}{d_{1}}
$$

in which

$$
y=Q+(1-\beta) S
$$

\subsection{Total cost function}

The proposed model considers the traditional ordering and purchasing costs, and the additional emission costs that become part of the holding and transportation costs. There are inspection costs that come from a $100 \%$ quality inspection. Backorder and lost sales costs come due to inventory shortages. The ordering cost is $C_{o}$, while the purchasing cost according to the order size is $Q C_{p}$, and the inspection cost for the arrival lot is $Q C_{i}$. These costs are counted per cycle. The holding cost for perfect quality products consists of basic operational expenses $\left(h_{l}\right)$ and additional charges due to emissions. Based on the average electricity usage $(e)$, standard electricity emission $(E)$, carbon tax rate $\left(C_{t}\right)$, and the expected defective rate $(E[\alpha])$, for the perfect quality products we have

$$
C_{\mathrm{h} 1}=\left(h_{1}+e E C_{t}\right)\left(\frac{1}{2} \frac{(\mathrm{Q}-E[\alpha] Q-\mathrm{s} \beta)^{2}}{d_{1}}+\frac{E[\alpha] Q^{2}}{i}\right)
$$

Then, considering the inventory of the defective items during $t_{3}$, the holding cost for defective products is

$$
C_{\mathrm{h} 2}=\left(h_{2}+e E C_{t}\right) \frac{(E[\alpha] Q)^{2}}{2 d_{2}}
$$

Inspired from Wee and Daryanto (2020), the transportation costs considers emissions from fuel consumption, and consist of a fixed transportation setup cost $C_{d}$, fixed costs from the operation of a truck $\left(2 l f_{1}\left(C_{f} F C_{t}\right)\right)$, and variable costs from the truckload $\left(w Q l f_{2}\left(C_{f}+F C_{t}\right)\right)$. Therefore, the total transportation cost is

$$
C_{T}=C_{d}+2 l f_{1}\left(C_{f}+F C_{t}\right)+w Q l f_{2}\left(C_{f}+F C_{t}\right)
$$

The partial backorder cost is

$$
C_{B}=\frac{1}{2} \frac{C_{b} \beta s^{2}}{d_{1}}
$$

while the lost sales cost is

$$
C_{L}=C_{l}\left(\frac{\mathrm{s}^{2}}{2 d_{1}}-\frac{\beta \mathrm{s}^{2}}{2 d_{1}}\right)
$$

Finally, considering the expected value $E[\alpha]$, the total cost per cycle is

$$
\begin{aligned}
& E T C=C_{o}+Q C_{p}+Q C_{i}+\left(h_{1}+e E C_{t}\right)\left(\frac{1}{2} \frac{(Q-E[\alpha] Q-\mathrm{s} \beta)^{2}}{d_{1}}+\frac{E[\alpha] Q^{2}}{i}\right)+\left(h_{2}+e E C_{t}\right) \frac{(E[\alpha] Q)^{2}}{2 d_{2}}+\frac{1}{2} \frac{C_{b} \beta s^{2}}{d_{1}}+ \\
& C_{d}+2 l f_{1}\left(C_{f}+F C_{t}\right)+w Q l f_{2}\left(C_{f}+F C_{t}\right)+\quad C_{l}\left(\frac{\mathrm{s}^{2}}{2 d_{1}}-\frac{\beta \mathrm{s}^{2}}{2 d_{1}}\right) .
\end{aligned}
$$

\subsection{Total revenue function}

Considering the expected value $E[\alpha]$, we can calculate the expected total revenue per cycle. Take note that revenue comes 
from the perfect and defective items, we have

$$
E T R=(1-E[\alpha]) Q P_{p}+E[\alpha] Q P_{d}
$$

\subsection{Total profit function}

From the Eq. (7), Eq. (14), and Eq. (15), the expected total profit per unit of time is

$E T P U=\frac{E T R-E T C}{E[T]}$,

hence,

$$
\begin{array}{r}
(1-\mathrm{E}[\alpha]) Q P_{p}+E[\alpha] Q P_{d}-C_{o}-Q C_{p}-Q C_{i}-\left(h_{1}+e E C_{t}\right) \\
\left(\frac{1}{2} \frac{(Q-E[\alpha] Q-\mathrm{s} \beta)^{2}}{d_{1}}+\frac{E[\alpha] Q^{2}}{i}\right)-\left(h_{2}+\mathrm{e} E C_{t}\right) \frac{(E[\alpha] \mathrm{Q})^{2}}{2 d_{2}}-\frac{1}{2} \frac{C_{b} \beta s^{2}}{d_{1}}- \\
E T P U=\frac{C_{d}-2 l f_{1}\left(C_{f}+F C_{t}\right)-w Q l f_{2}\left(C_{f}+F C_{t}\right)-C_{l}\left(\frac{\mathrm{s}^{2}}{2 d_{1}}-\frac{\beta \mathrm{s}^{2}}{2 d_{1}}\right)}{\frac{(1-E[\alpha]) Q+(1-\beta) s}{d_{1}}}
\end{array}
$$

The concavity check for this total profit function is conducted as follows:

$$
\begin{aligned}
& \frac{\partial^{2} E T P U}{\partial s^{2}}=-\frac{h_{1} \beta^{2}+\mathrm{e} E C_{t} \beta^{2}+C_{b} \beta+C_{l}-C_{l} \beta}{Q} \frac{1}{1-E[\alpha]} \\
& \frac{\partial^{2} E T P U}{\partial y^{2}}=\left(\begin{array}{c}
s^{2} \frac{h_{1} \beta^{2}+\mathrm{e} E C_{t} \beta^{2}+C_{l}}{Q^{3}}+\beta s^{2} \frac{C_{b}-C_{l}}{Q^{3}} \\
+2 d_{1} \frac{C_{o}+C_{d}+2 l f_{1}\left(F C_{t}+C_{f}\right)}{Q^{3}}
\end{array}\right) \frac{1}{E[\alpha]-1} \\
& \frac{\partial^{2} E T P U}{\partial s \partial Q}=-\frac{s\left(h_{1} \beta^{2}+\mathrm{e} E C_{t} \beta^{2}+C_{b} \beta+C_{l}-C_{l} \beta\right)}{(E[\alpha]-1) Q^{2}} \\
& \left(\frac{\partial^{2} E T P U}{\partial s \partial Q}\right)^{2}-\left(\frac{\partial^{2} E T P U}{\partial b^{2}}\right)\left(\frac{\partial^{2} E T P U}{\partial y^{2}}\right) \\
& =-\frac{2\left(e E C_{t} \beta^{2}+h_{1} \beta^{2}+C_{b} \beta-C_{l} \beta+C_{l}\right) d_{1}\left(C_{o}+C_{d}+2 l f_{1}\left(F C_{t}+C_{f}\right)\right.}{Q^{4}} \frac{1}{(E[\alpha]-1)^{2}} \leq 0
\end{aligned}
$$

These results have shown that ETPU is strictly concave.

\subsection{Optimal decisions}

Because ETPU is strictly concave, the optimal values of $s^{*}$ and $Q^{*}$ can be obtained as follows:

$$
\begin{aligned}
& s^{*}=\frac{\left(h_{1} \beta+\mathrm{e} E C_{t} \beta\right) Q(1-E[\alpha])}{\left(e E C_{t} \beta^{2}+h_{1} \beta^{2}+C_{b} \beta-C_{l} \beta+C_{l}\right)}
\end{aligned}
$$

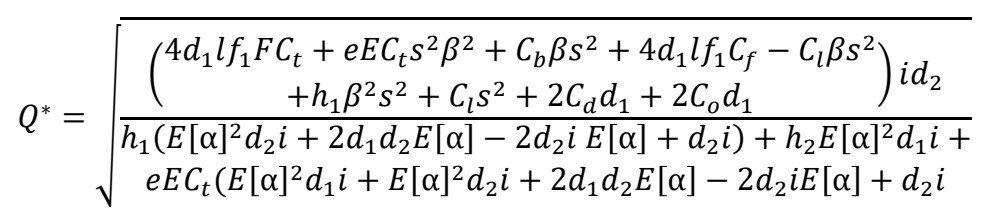

Further, to study the effect of the above decisions on carbon emissions reduction, we can calculate the expected total emissions (ETE) per unit time from Eq. (9), Eq. (10), and Eq. (11).

$$
E T E=\left(\begin{array}{c}
e E\left(\frac{1}{2} \frac{(Q-E[\alpha] Q-s \beta)^{2}}{d_{1}}+\frac{E[\alpha] Q^{2}}{i}\right)+ \\
\mathrm{e} E \frac{(E[\alpha] Q)^{2}}{2 d_{2}}+2 l f_{1} F+w Q l f_{2} F
\end{array}\right)\left(\frac{d_{1}}{(1-E[\alpha]) Q+(1-\beta) s}\right)
$$




\section{Numerical illustration and discussion}

An example is presented to illustate the decision process. A set of data is provided by adapting Teng \& Hsu (2013) and Wee $\&$ Daryanto (2020). Considers a set of data as follows:

$d_{1}=50.000, d_{2}=30.000, P_{p}=50, P_{d}=40, i=175, w=0.01, \beta=0.7, h_{1}=10, h_{2}=8, C_{o}=100, C_{b}=20, C_{p}=25, C_{i}=0.5$, $C_{t}=75, C_{d}=100, C_{l}=25, C_{f}=0.75, l=10, f_{l}=0,27, f_{2}=0.0057, e=1.44, F=2.6 \times 10^{-3}, E=0.5 \times 10^{3}$, and $E[\alpha]=0.02$

For the above data set, Eq. (21) and Eq. (2) give the optimal results of $s^{*}=580.3$ units, $Q^{*}=1770.1$ units, ETPU $=\$$ $1,227,945$ per year, and $E T E=0.765$ tonCO $2 /$ year. Substituting $C_{t}=0$, for a system without emission tax we gain new results of $s^{*}=577.8$ units, $Q^{*}=1768.8$ units with the $E T P U=\$ 1,228,002$ per year and $E T E=0.766$ tonCO $\mathrm{CO}_{2} /$ year. From the above results, we found that carbon emission regulation reduces the company's profit but successfully reduces the carbon emissions. Further, a sensitivity analysis is conducted by changing the value of each parameter between $-20 \%$ to $+20 \%$ when the remaining parameters remain constant. Table 2 presents the results and shows the changing values in $s^{*}$, $Q^{*}, E T E$, and ETPU.

Table 2

Sensitivity analysis results

\begin{tabular}{|c|c|c|c|c|c|}
\hline Parameter & $\%$ change & $s^{*}$ (units) & $Q^{*}$ (units) & $\operatorname{ETE}\left(\right.$ tonCO $\left.\mathrm{O}_{2}\right)$ & $E T P U(\$)$ \\
\hline$d_{l}$ & +20 & 457.8 & $1,754.0$ & 1.000 & $1,473,403.7$ \\
\hline \multirow[t]{3}{*}{$(50000)$} & +10 & 438.6 & $1,680.6$ & 0.953 & $1,350,046.7$ \\
\hline & -10 & 397.3 & $1,522.5$ & 0.853 & $1,103,419.5$ \\
\hline & -20 & 374.9 & $1,436.5$ & 0.800 & $980,159.0$ \\
\hline$d_{2}$ & +20 & 418.5 & $1,603.7$ & 0.904 & $1,226,718.0$ \\
\hline \multirow[t]{3}{*}{$(30000)$} & +10 & 418.5 & $1,603.6$ & 0.904 & $1,226,717.6$ \\
\hline & -10 & 418.5 & $1,603.5$ & 0.904 & $1,226,716.7$ \\
\hline & -20 & 418.5 & $1,603.5$ & 0.904 & $1,226,716.1$ \\
\hline$P_{p}$ & +20 & 418.5 & $1,603.6$ & 0.903 & $1,726,717.2$ \\
\hline \multirow[t]{3}{*}{ (50) } & +10 & 418.5 & $1,603.6$ & 0.904 & $1,476,717.2$ \\
\hline & -10 & 418.5 & $1,603.6$ & 0.905 & $976,717.2$ \\
\hline & -20 & 418.5 & $1,603.6$ & 0.906 & $726,717.2$ \\
\hline$P_{d}$ & +20 & 418.5 & $1,603.6$ & 0.919 & $1,234880.5$ \\
\hline \multirow[t]{3}{*}{ (40) } & +10 & 418.5 & $1,603.6$ & 0.911 & $1,230,798.9$ \\
\hline & -10 & 418.5 & $1,603.6$ & 0.896 & $1,222,635.6$ \\
\hline & -20 & 418.5 & $1,603.6$ & 0.889 & $1,218,554.0$ \\
\hline$i$ & +20 & 419.0 & $1,605.5$ & 1.008 & $1,226,732.9$ \\
\hline \multirow[t]{3}{*}{$(175200)$} & +10 & 418.8 & $1,604.6$ & 0.956 & $1,226,725.8$ \\
\hline & -10 & 418.2 & $1,602.3$ & 0.852 & $1,226,706.8$ \\
\hline & -20 & 417.8 & $1,600.7$ & 0.799 & $1,226,693.8$ \\
\hline$w$ & +20 & 418.5 & $1,603.6$ & 0.993 & $1,226,711.7$ \\
\hline \multirow[t]{3}{*}{$(0,01)$} & +10 & 418.5 & $1,603.6$ & 0.949 & $1,226,714.5$ \\
\hline & -10 & 418.5 & $1,603.6$ & 0.859 & $1,226,720.0$ \\
\hline & -20 & 418.5 & $1,603.6$ & 0.815 & $1,226,722.7$ \\
\hline$C_{0}$ & +20 & 438.5 & $1,680.0$ & 0.917 & $1,226,095.7$ \\
\hline \multirow[t]{3}{*}{$(100)$} & +10 & 428.6 & $1,642.2$ & 0.910 & $1,226,402.8$ \\
\hline & -10 & 408.2 & $1,564.0$ & 0.898 & $1,227,039.4$ \\
\hline & -20 & 397.6 & $1,523.4$ & 0.893 & $1,227,369.9$ \\
\hline$C_{b}$ & +20 & 374.4 & $1,586.5$ & 1.000 & $1,226,576.9$ \\
\hline \multirow[t]{3}{*}{ (20) } & +10 & 395.2 & $1,594.6$ & 0.952 & $1,226,643.3$ \\
\hline & -10 & 444.8 & $1,613.8$ & 0.856 & $1,226,799.9$ \\
\hline & -20 & 474.5 & $1,625.5$ & 0.809 & $1,226,892.9$ \\
\hline$C_{p}$ & +20 & 418.5 & $1,603.6$ & 1.008 & $971,615.2$ \\
\hline \multirow[t]{3}{*}{ (25) } & +10 & 418.5 & $1,603.6$ & 0.956 & $1,073,656.0$ \\
\hline & -10 & 418.5 & $1,603.6$ & 0.852 & $1,328,758.0$ \\
\hline & -20 & 418.5 & $1,603.6$ & 0.799 & $1,481,819.3$ \\
\hline$h_{1}$ & +20 & 449.9 & $1,491.1$ & 0.952 & $1,225,732.7$ \\
\hline \multirow[t]{3}{*}{ (10) } & +10 & 434.8 & $1,543.3$ & 0.929 & $1,226,207.2$ \\
\hline & -10 & 400.9 & $1,674.3$ & 0.875 & $1,227,268.1$ \\
\hline & -20 & 381.8 & $1,758.5$ & 0.844 & $1,227,866.8$ \\
\hline$h_{2}$ & +20 & 418.5 & $1,603.5$ & 0.870 & $1,226,716.1$ \\
\hline \multirow[t]{3}{*}{ (8) } & +10 & 418.5 & $1,603.5$ & 0.887 & $1,226,716.8$ \\
\hline & -10 & 418.5 & $1,603.6$ & 0.921 & $1,226,717.7$ \\
\hline & -20 & 418.6 & $1,603.7$ & 0.939 & $1,226,718.3$ \\
\hline$\overline{C_{i}}$ & +20 & 418.5 & $1,603.6$ & 0.898 & $1,221,615.2$ \\
\hline \multirow[t]{3}{*}{$(0.5)$} & +10 & 418.5 & $1,603.6$ & 0.898 & $1,224,166.2$ \\
\hline & -10 & 418.5 & $1,603.6$ & 0.898 & $1,229,268.2$ \\
\hline & -20 & 418.5 & $1,603.6$ & 0.898 & $1,231,819.3$ \\
\hline
\end{tabular}


Table 2

Sensitivity analysis results (Continued)

\begin{tabular}{|c|c|c|c|c|c|}
\hline$C_{t}$ & +20 & 418.9 & $1,603.7$ & 0.904 & $1,226,703.7$ \\
\hline \multirow[t]{3}{*}{ (75) } & +10 & 418.7 & $1,603.7$ & 0.904 & $1,226,710.0$ \\
\hline & -10 & 418.3 & $1,603.5$ & 0.904 & $1,226,723.5$ \\
\hline & -20 & 418.1 & $1,603.5$ & 0.904 & $1,226,730.8$ \\
\hline$C_{d}$ & +20 & 438.5 & $1,680.0$ & 0.902 & $1,226,095.7$ \\
\hline \multirow[t]{3}{*}{$(100)$} & +10 & 428.6 & $1,642.2$ & 0.903 & $1,226,402.8$ \\
\hline & -10 & 408.2 & $1,564.0$ & 0.906 & $1,227,039.4$ \\
\hline & -20 & 397.6 & $1,523.4$ & 0.908 & $1,227,369.9$ \\
\hline$l$ & +20 & 419.6 & $1,607.6$ & 0.904 & $1,226,679.3$ \\
\hline \multirow[t]{3}{*}{ (10) } & +10 & 419.0 & $1,605.6$ & 0.904 & $1,226,698.2$ \\
\hline & -10 & 418.0 & $1,601.6$ & 0.904 & $1,226,736.2$ \\
\hline & -20 & 417.5 & $1,599.6$ & 0.904 & $1,226,755.2$ \\
\hline \multirow{4}{*}{$\begin{array}{c}C_{f} \\
(0.75)\end{array}$} & +20 & 419.3 & $1,606.8$ & 0.904 & $1,226,687.1$ \\
\hline & +10 & 418.8 & $1,604.6$ & 0.904 & $1,226,707.2$ \\
\hline & -10 & 418.2 & $1,602.5$ & 0.904 & $1,226,727.3$ \\
\hline & -20 & 417.7 & $1,600.4$ & 0.904 & $1,226,747.4$ \\
\hline \multirow{4}{*}{$\begin{array}{c}f_{l} \\
(0.75)\end{array}$} & +20 & 419.5 & $1,607.3$ & 0.904 & $1,226,687.2$ \\
\hline & +10 & 419.1 & $1,605.8$ & 0.904 & $1,226,699.2$ \\
\hline & -10 & 417.9 & $1,601.4$ & 0.904 & $1,226,735.3$ \\
\hline & -20 & 417.6 & $1,599.9$ & 0.904 & $1,226,747.3$ \\
\hline \multirow{4}{*}{$\begin{array}{c}f_{2} \\
(0.75)\end{array}$} & +20 & 418.5 & $1,603.6$ & 0.904 & $1,226,711.9$ \\
\hline & +10 & 418.5 & $1,603.6$ & 0.904 & $1,226,714.3$ \\
\hline & -10 & 418.5 & $1,603.6$ & 0.904 & $1,226,720.1$ \\
\hline & -20 & 418.5 & $1,603.6$ & 0.904 & $1,226,722.5$ \\
\hline$e$ & +20 & 418.7 & $1,602.9$ & 0.904 & $1,226,711.5$ \\
\hline \multirow[t]{3}{*}{$(0.75)$} & +10 & 418.6 & $1,603.2$ & 0.904 & $1,226,714.4$ \\
\hline & -10 & 418.4 & $1,603.9$ & 0.904 & $1,226,720.1$ \\
\hline & -20 & 418.3 & $1,604.3$ & 0.904 & $1,226,723.0$ \\
\hline$F$ & +20 & 418.7 & $1,604.4$ & 0.904 & $1,226,709.7$ \\
\hline \multirow[t]{3}{*}{$(0.75)$} & +10 & 418.6 & $1,604.1$ & 0.904 & $1,226,712.7$ \\
\hline & -10 & 418.4 & $1,603.1$ & 0.904 & $1,226,721.7$ \\
\hline & -20 & 418.3 & $1,602.8$ & 0.904 & $1,226,724.8$ \\
\hline$E$ & +20 & 418.7 & $1,602.9$ & 0.904 & $1,226,711.5$ \\
\hline \multirow[t]{3}{*}{$(0.75)$} & +10 & 418.6 & $1,603.2$ & 0.904 & $1,226,714.4$ \\
\hline & -10 & 418.4 & $1,603.9$ & 0.904 & $1,226,720.1$ \\
\hline & -20 & 418.3 & $1,604.3$ & 0.904 & $1,226,722.9$ \\
\hline \multirow{4}{*}{$\begin{array}{c}C_{l} \\
(0.75)\end{array}$} & +20 & 393.7 & $1,594.0$ & 0.914 & $1,226,638.4$ \\
\hline & +10 & 403.2 & $1,597.7$ & 0.910 & $1,226,668.8$ \\
\hline & -10 & 429.4 & $1,607.8$ & 0.900 & $1,226,751.5$ \\
\hline & -20 & 446.8 & $1,614.6$ & 0.893 & $1,226,806.1$ \\
\hline \multirow{4}{*}{$\begin{array}{c}\beta \\
(0.75)\end{array}$} & +20 & 496.7 & $1,673.9$ & 0.878 & $1,227,265.1$ \\
\hline & +10 & 458.1 & $1,637.1$ & 0.890 & $1,226,984.2$ \\
\hline & -10 & 378.0 & $1,573.4$ & 0.919 & $1,226,466.9$ \\
\hline & -20 & 336.6 & $1,546.5$ & 0.935 & $1,226,235.8$ \\
\hline \multirow{4}{*}{$\begin{array}{l}E[\alpha] \\
(0.75)\end{array}$} & +20 & 417.8 & $1,607.5$ & 0.904 & $1,229,727.4$ \\
\hline & +10 & 418.2 & $1,605.6$ & 0.904 & $1,228,219.3$ \\
\hline & -10 & 418.9 & $1,601.6$ & 0.904 & $1,225,221.2$ \\
\hline & -20 & 419.2 & $1,599.7$ & 0.903 & $1,223,731.0$ \\
\hline
\end{tabular}

The above results lead to several insights as follows:

a. Total profit is highly affected by the changes in demand and selling price of perfect items, in which the increase is proportional. The effect of demand on defective products is very low. It may happen when the percentage of defective products is low, hence does not give a significant contribution.

b. The effect of purchasing cost on the total profit is the highest compared to the other cost parameters, followed by the inspection cost and holding cost of perfect products. It happens because these costs are charged to all of the products at the beginning. Therefore, a careful search to find the best supplier and best inspection method are then essential. The possibility to do a sampling inspection can be further studied.

c. The total profit is also highly affected by the percentage of defective products, hence a search to find the best supplier or collaboration to improve supplier's quality is highly recommended.

d. The total emissions are proportionally affected by the demand for perfect products, inspection rate, product weight, backorder cost, purchasing cost, and holding cost for the perfect products. The total emissions are inversely affected by the holding cost of the defective products and the percentage of the backorder. The changes in other parameters do not affect the total emissions. Surprisingly, the changes in the carbon tax rate do not affect the total emissions. 


\section{Conclusions}

This paper presents a study on the low carbon EOQ model by simultaneously considering the effect of defective products and partial backorder. The model assumes a separation between the perfect and defective products, followed by different demand rates, selling price, and holding cost for defective products. The retailer is obligated to the carbon tax regulation, hence the total cost incorporates carbon emissions cost that comes from transportation and inventory activities.

The study found that carbon emission regulation successfully reduces carbon emissions but reduces the company's profit. But surprisingly, the changes in the carbon tax rate do not affect the total emissions. Therefore, the government must be careful in setting tax rates so that the goal of reducing carbon emissions is achieved without harming businesses. Total profit is highly affected by the changes in demand and selling price of perfect items, purchasing cost, inspection cost, and holding cost. Therefore, managers must monitor these costs carefully. Further research on selling price policies could also be a solution to this situation. The total emissions are proportionally affected by the demand for perfect products, inspection rate, product weight, backorder cost, purchasing cost, and holding cost for the perfect products.

The proposed model has certain limitations. The study only works for carbon tax regulation; hence, the model can be extended in several ways by implementing other carbon reduction regulations, e.g., cap policies and cap-and-trade systems. Regarding the defective products, further research can study the effect of sampling inspection and product repair. Several recent studies have investigated the effect of green technology investment as in Mashud et al. (2020, 2021) and Mishra et al. $(2020,2021)$, this can also be applied in this proposed model.

\section{Acknowledgment}

The authors thank Universitas Atma Jaya Yogyakarta for supporting this research by providing a research grant in 2020 . The authors also thank the editor and reviewers.

\section{References}

Battini, D., Persona, A., \& Sgarbossa, F. (2014). A sustainable EOQ model: theoretical formulation and applications. International Journal of Production Economics, 149, 145-153.

Benjaafar, S., Li, Y., \& Daskin, M. (2013). Carbon footprint and the management of supply chains: Insights from simple models. IEEE Transactions on Automation Science and Engineering, 10(1), 99-116.

Bonney, M., \& Jaber, M.Y. (2011). Environmentally responsible inventory models: non-classical models for a non-classical era. International Journal of Production Economics, 133(1), 43-53.

Chen, X., Benjaafar, S., \& Elomri, A. (2013). The carbon-constrained EOQ. Operations Research Letters, 41, $172-179$.

Daryanto, Y., Christata, B.R., \& Kristiyani, I.M. (2020). Retailer's EOQ model considering demand and holding cost of the defective items under carbon emission tax. IOP Conference Series: Material Science \& Engineering, 847, 012012.

Digiesi, S., Mossa, G., \& Rubino, S. (2012). Sustainable order quantity of repairable spare parts, In Proceeding of the $2^{\text {nd }}$ IFAC Workshop on Advanced Maintenance Engineering, Services and Technology, Sevilla, Spain, November 22-23, 2012.

Hua, G.W., Cheng, T.C.E., Zhang, Y., Zhang, J.L., \& Wang, S.Y. (2016). Carbon-constrained perishable inventory management with freshness-dependent demand. International Journal of Simulation Modelling, 15(3), 542-552.

Kazemi, N., Abdul-Rashid, S.H., Ghazilla, R.A.R., Shekarian, E., \& Zanoni, S. (2018). Economic order quantity models for items with imperfect quality and emission considerations. International Journal of Systems Science: Operations \& Logistics, 5(2), 99-115.

Lee, K., Yoo, S.H., \& Cheong, T. (2017). Sustainable EOQ under lead-time uncertainty and multi-modal transport. Sustainability, 9(3), 476.

Maddah, B. \& Jaber, M.Y. (2008). Economic order quantity for items with imperfect quality: Revisited. International Journal of Production Economics, 112(2), 808-815.

Mashud, A.H.M., Roy, D., Daryanto, Y., \& Ali, M.H. (2020). A sustainable inventory model with imperfect products, deterioration, and controllable emissions. Mathematics, 8, 11, 2049.

Mashud, A.H.M., Roy, D., Daryanto, Y., Chakrabortty, R.K., \& Tseng, M.L. (2021). A sustainable inventory model with controllable carbon emissions, deterioration and advance payments. Journal of Cleaner Production, Article In Press.

Mishra, U., Wu, J.Z., \& Sarkar, B. (2021). Optimum sustainable inventory management with backorder and deterioration under controllable carbon emissions. Journal of Cleaner Production, 279, 123699.

Mishra, U., Wu, J.Z., Tsao, Y.C., \& Tseng, M.L. (2020). Sustainable inventory system with controllable non-instantaneous deterioration and environmental emission rates. Journal of Cleaner Production, 244, 118807.

Porteus, E.L. (1986). Optimal lot sizing, process quality improvement and setup cost reduction. Operations Research, 34(1), 137-144.

Rosenblatt, M.J., \& Lee, H.L. (1986). Economic production cycles with imperfect production processes. IIE Transactions, 18(1), 48-55.

Salameh, M.K., \& Jaber, M.Y. (2000). Economic production quantity model for items with imperfect quality. International Journal of Production Economics, 64(1), 59-64. 
Schwaller, R.L. (1988). EOQ under inspection costs. Production and Inventory Management Journal, 29(3), 22-24.

Soleymanfar, V.R., Taleizadeh, A.A., \& Zia, N.P. (2015). A sustainable lot-sizing model with partial backordering. International Journal of Advanced Operations Management, 7(2), 157-172.

Taleizadeh, A.A., Hazarkhani, B., \& Moon, I. (2020). Joint pricing and inventory decisions with carbon emission considerations, partial backordering and planned discounts. Annals of Operations Research, 290(1-2), 95-113.

Teng, H.M., \& Hsu, P.H. (2013). Revisit economic ordering strategy for items with imperfect quality and backordering. International Journal of Management and Enterprise Development, 12(3), 251-262.

Wahab, M.I.M., \& Jaber, M.Y. (2010). Economic order quantity model for items with imperfect quality, different holding costs, and learning effects: A note. International Journal of Production Economics, 58(1), 186-190.

Wangsa, I.D. (2017). Greenhouse gas penalty and incentive policies for a joint economic lot size model with industrial and transport emissions. International Journal of Industrial Engineering Computation, 8(1), 453-480.

Wee, H.M., \& Daryanto, Y. (2020). Imperfect quality item inventory models considering carbon emissions, In Shah, N.H., \& Mittal, M. (eds.). Optimization and Inventory Management, Singapore: Springer Nature, 137-159.

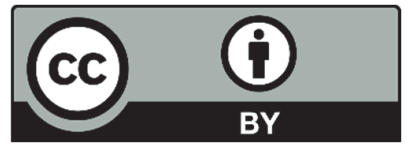

(C) 2021 by the authors; licensee Growing Science, Canada. This is an open access article distributed under the terms and conditions of the Creative Commons Attribution (CC-BY) license (http://creativecommons.org/licenses/by/4.0/). 